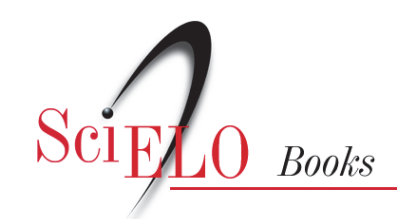

\title{
A teologia e a literatura de Borges:
}

um diálogo

\author{
Andréa Padrão
}

FERRAZ, S., et al.,orgs. Deuses em poéticas: estudos de literatura e teologia [online]. Belém: UEPA; Campina Grande: EDUEPB, 2008. 364 p. ISBN 978-85-7879-010-3. Available from SciELO Books $<\underline{\text { http://books.scielo.org }>\text {. }}$

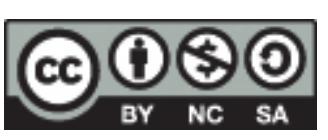

All the contents of this work, except where otherwise noted, is licensed under a Creative Commons Attribution-Non Commercial-ShareAlike 3.0 Unported.

Todo o conteúdo deste trabalho, exceto quando houver ressalva, é publicado sob a licença Creative Commons Atribuição Uso Não Comercial - Partilha nos Mesmos Termos 3.0 Não adaptada.

Todo el contenido de esta obra, excepto donde se indique lo contrario, está bajo licencia de la licencia Creative Commons Reconocimento-NoComercial-CompartirIgual 3.0 Unported. 


\section{A teologia e a literatura de Borges: um diálogo}

Andréa Padrão 


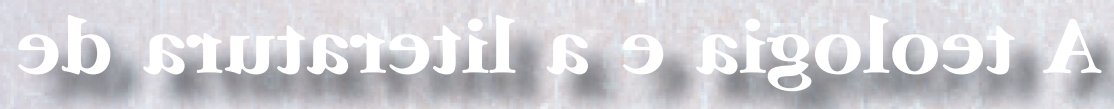

$$
\text { ogolshib mus :29870d }
$$

oūiblog nónbora 
Resumo: De todos os escritores hispano-americanos, Jorge Luis Borges talvez seja, segundo Molloy (1987, p. 801), o mais imponente, o mais disponível para o mito. Escrevendo somente ensaios, poemas e relatos breves, Borges conseguiu produzir uma literatura fantástica e abstrata, universalmente reconhecida, e criar um mundo particular dotado de uma estética pessoal e conceitos próprios, no qual são freqüentes as manifestações religiosas que se nutrem na Bíblia, na Cabala, na tradição, na teologia e na filosofia. $\mathrm{O}$ presente artigo analisa sucintamente a singular atração de Borges pela Bíblia, pela Cabala e pelo mundo judeu; enfoca, também, algumas questões teológicas recorrentes nos diversos gêneros pelos quais o escritor transitou, notadamente na narrativa ficcional.

Palavras-chave: Borges, teologia, literatura.

Abstract: Of all Latin-American writers, Jorge Luis Borges may have been, according to Molloy $(1987$, p. 801), the grandest, the most apt for myth. Having written only essays, poems and short stories, Borges did more than produce literature that is both fantastic and abstract, besides being universally recognized. He was also able to create a particular world endowed with personal aesthetics and private concepts in which one can often find religious manifestations embedded in the Bible, in Kabbalah, in theology and in philosophy. The present work briefly analyses the singular attraction Borges felt towards the Bible, Kabbalah and the Jewish world. It also focuses on some recurring theological issues found in the author's different texts, mainly his fictional narrative.

Keywords: Borges, theology, literature.

*Professora da Universidade Federal de Santa Catarina - Pós-Graduação em Estudos da Tradução. Linha de pesquisa: teoria, crítica e história da tradução. andreapadrao@gmail. com 
Jorge Luis Borges, além brilhante escritor, foi também um insaciável leitor. Leu a respeito dos mais diversos assuntos e se vangloriou disso; tanto que em diversas oportunidades declarou que se orgulhava mais das leituras que havia feito do que daquilo que tinha escrito. Suas inumeráveis e inesperadas fontes de leitura são responsáveis diretas pela fascinante vastidão da sua obra. Em seus numerosos contos, ensaios e poemas o autor argentino acolhe de tudo, inclusive importantes questões teológicas, muitas vezes tangenciadas, outras vezes abordadas diretamente. Essa relação da literatura de Borges com a teologia tem causado, muitas vezes, assombro em seus leitores e polêmicas entre os especialistas. Neste artigo, além de refletir sobre a singular atração de Borges pelas Sagradas Escrituras e pelo mundo judeu, aponto e discuto brevemente algumas questões teológicas recorrentes nos diversos gêneros pelos quais o escritor transitou, notadamente na narrativa ficcional.

Uma característica da literatura borgiana, além da variedade de temas abordados, consiste no uso de citações apócrifas, de bibliografia inventada, de plágio, inclusive para conferir maior autenticidade a seus textos ficcionais ou aspecto científico a seus ensaios. Na verdade, a falsificação e a relativização dos gêneros, tão habituais em Borges, guardam o propósito comum de converter toda sua literatura num enorme enigma intelectual do qual o leitor é um jogador que participa ativamente, quer seja decifrando o mistério em seus contos, quer seja buscando o valor de suas mensagens no conjunto de sua obra, ou, ainda, estabelecendo ligações com outros autores e outras obras como a Bíblia, a Cabala, o Corão, De Quincey, Schopenhauer, Stevenson, Poe, Kipling, Spinoza, Chesterton e tantos mais. Assim, uma das marcas registradas da literatura de Borges é a habilidade com que ele manipula o cepticismo, considerado uma das melhores ferramentas para criar suas ficções.

Em "Pierre Menard, autor del Quijote", o narrrador não esconde a técnica habilmente utilizada:

Menard, (acaso sin quererlo) ha enriquecido mediante una técnica nueva, el arte detenido y rudimentario de la lectura: la técnica del anacronismo deliberado y de las atribuciones erróneas (Borges, 1996, p. 498).

Então o leitor borgiano naturalmente é um leitor desconfiado, sabedor de que deve sempre conferir a veracidade dos fatos narrados, uma vez que Borges, autor inconfiável, inúmeras vezes, ao longo de 
sua extensa obra, revela-se um céptico:

Yo no tengo ninguna teoría del mundo. En general, como yo he usado los diversos sistemas metafísicos y teológicos para fines literarios, los lectores han creído que yo profesaba esos sistemas, cuando realmente lo único que he hecho ha sido aprovecharlos para esos fines, nada más. Además, si yo tuviera que definirme, me definiría como un agnóstico, es decir, una persona que no cree que el conocimiento sea posible (Borges in Vázquez, 1977, p.107).

A declaração de cepticismo, temperada com uma dose de ironia, também está presente quando ele afirma que todo homem culto é um teólogo, e para sê-lo não é indispensável a fé (Borges, 1996, p. 110, v.II).

Ao longo de toda sua carreira literária Borges circula por um grande número de filósofos, acompanhando com profundo interesse $\mathrm{o}$ debate filosófico; da mesma forma, dedica-se à teologia, assunto quase sempre presente em artigos, ensaios e contos. De tal forma que, podese afirmar, grande parte da originalidade de Borges reside no delicado processo de fazer literatura com as especulações filosóficas e com as doutrinas teológicas, apresentando-as não como verdades incontestáveis, mas como fontes literárias, invenções ou criações da desassossegada imaginação dos homens.

O próprio Borges reconhece essa peculiaridade de sua literatura, referindo-se a ela numerosas vezes ao longo de sua extensa obra. No Epílogo de Otras Inquisiciones, por exemplo, confessa sua inclinação para estimar as idéias religiosas ou filosóficas por seu valor estético e pelo que encerram de singular e de maravilhoso (Borges, 1996, p.153, v.II).

Apesar de toda essa declarada incredulidade, as Sagradas Escrituras aparecem como uma das fontes primeiras de inspiração borgiana; além de importantes ferramentas estéticas, são textos carregados de mistério, de esoterismo, de problemas metafísicos. A leitura da Bíblia, desde a infância, proporcionou-lhe também o conhecimento da cultura judaica, com quem se identificou até pensar-se freqüentemente como judeu. ${ }^{64}$ Assim, muitas das suas narrativas foram influenciadas por sua 64 Com avó paterna protestante - cultora da Bíblia, que lhe abriu as portas da cultura judaica - pai ateu e mãe católica, Borges foi criado num ambiente religioso; no entanto, apesar disso, geralmente se apresentava como um cético. 
declarada simpatia pelos judeus, tendo, em diversas oportunidades, expressado o desejo de encontrar em sua linhagem sangue judeu. "Yo siempre he hecho todo lo posible por ser judío. Siempre he buscado antepasados judíos. La familia de mi madre es Acevedo, y podría ser judía portuguesa". Ou, ainda, "Si pertecenemos a la civilización occidental, entonces todos nosotros, a pesar de las muchas aventuras de la sangre, somos griegos y judíos". ${ }^{65}$ É possível verificar que interessam a Borges não somente as idéias concebidas no judaísmo, mas também as circunstâncias do homem judeu de carne e osso. Segundo Muñoz Rengel ${ }^{66}$, Borges admirava os judeus como um povo que, durante a Segunda Guerra Mundial, foi identificado com o intelecto e a espiritualidade, em oposição à brutalidade absoluta e à maldade infernal dos nazistas. Os judeus, para Borges, são os criadores da cultura, os malditos, os sacrificados, os que têm ao Livro como pátria portátil; porém, são também os que, admirando Deus, ousam desafiá-lo. Ao longo de sua carreira literária, encontramos judeus pelos quais Borges professa veneração, como Kafka, Cansinos-Asséns, Spinoza. Ou como Jesus Cristo, objeto especial de sua consideração. No diálogo com Vázquez, referido anteriormente, Borges demonstra profunda admiração por Jesus Cristo, homem justo e extraordinário, a quem considera, indubitavelmente, uma das pessoas mais raras e mais admiráveis do mundo. Apesar desse respeito, de forma irônica mostra-se descrente da religião professada pelos seus seguidores, ao afirmar que não sabe se os cristãos se parecem com Cristo (Borges in Vázquez, 1977, p. 91-2).

Borges utiliza seu conhecimento do judaísmo para criar uma verdadeira galeria de personagens judaicos em seus contos. Em "Emma Zunz", por exemplo, conto que trata do assassinato de Aaron Loewenthal, cometido pela jovem Emma Zunz para vingar a morte do seu pai, o prenome feminino Emma pode ser lido como um hipocorístico do nome do pai Emanuel, nome hebreu (Emmanuel) que significa "Deus conosco" (Mateus 1:23) - o que justificaria o fato de ela se considerar uma espécie de instrumento da Justiça de Deus. Note-se que ela arma o corajoso estratagema que permitiria à Justiça de Deus triunfar sobre a justiça humana. A outra personagem do texto, Aaron, também possui um nome bíblico judeu, que remete ao irmão de Moisés, idólatra de um bezerro de ouro (Êxodo 32). No caso de Loewenthal, esse deus era

65 Tais afirmativas de Borges estão contidas em Munõz Rangel, En qué creía Borges. S.d. Disponível em http://members.fortunecity.com/mundopoesia2/articulos/enquecreiaborges.htm. Acesso em 28/mar/2007.

66 Idem. 
o dinheiro:

Aarón Loewenthal era, para todos, un hombre serio; para sus pocos íntimos, un avaro. (...) Había llorado con decoro, el año anterior, la inesperada muerte de su mujer - una Gauss, que le trajo una buena dote - pero el dinero era su verdadera pasión. (Borges, 1996, p.566 v.I)

Nessa descrição de Loewenthal está presente de forma marcante a ironia borgiana; o chorar com decoro, para manter as aparências, não esconde os reais sentimentos: o dinheiro era sua verdadeira paixão. Aaron Loewenthal representa, pois, a típica personagem de costume ${ }^{67}$ dominada quase com exclusividade por um traço distintivo: a avareza.

Vivía en los altos de la fábrica, solo. Establecido en el desmantelado arrabal, temía a los ladrones; en el patio de la fábrica había un gran perro y en el cajón de su escritorio, nadie lo ignoraba, un revólver (Borges, 1996, p. 566 v.I).

Além de avarento e usurário, ele também vive uma falsa religiosidade; era muito religioso e acreditava ter com o Senhor um pacto secreto, que o eximia de agir bem a troco de orações e devoções. Notese que ao introduzir os personagens judeus em seus contos, Borges não se furta, inclusive, a apresentá-los com os estereótipos negativos freqüentemente associados ao judeu típico.

Os nomes de outras personagens do conto (Manuel Maier, Elsa Urstein, Perla Kronfuss, Gauss, Fein ou Fain) também são de ascendência judaica. Registre-se que a única personagem não-judaica é o sueco ou norueguês com quem Emma perde sua virgindade, escolhido por ser um estrangeiro (que nem sequer fala espanhol), marinheiro do barco Nordstjärnan, de Malmö.

Um outro tópico religioso presente em "Emma Zunz", o copo de água que Emma pede a Loewenthal com o objetivo de fazê-lo sair da sala para que ela pegue o revólver, pode significar, como no episódio bíblico em que Pôncio Pilatos lava as mãos (Mateus 27:24), uma intenção de se eximir de culpa pelo ato que vai praticar; ou, ainda, um ato de purificação (considerando a importância simbólica da água, entre os judeus).

67 Em "Personagens do romance", Antonio Candido, citando Johnson, define "personagens de costume" como aquelas apresentadas por traços distintivos, fortemente marcados e desde logo revelados. (CANDIDO, 1998, p. 61). 
Também o dia da semana que Emma escolhe para sua vingança - o sábado - é significativo. O calendário judeu considera-o dia de descanso e dedicado a Jeová (Êxodo 20:8-11 e 31, 12). Para tornar mais terrível o seu sacrifício, nesse dia sagrado ela se prostitui, mata e mente. Também rasga o dinheiro com que foi paga pelo marinheiro.

Apesar dos estereótipos negativos com que muitas vezes Borges apresenta seus personagens judeus, uma das qualidades mais reiteradas desses personagens é a intelectualidade; geralmente são artistas, pessoas sensíveis e inteligentes, como o poeta judeu alemão David Jerusalém, no conto "Deutsches Requiem". Nele Borges enfoca não só o tema do duplo, mas o tema da morte e da confrontação política entre judeus e nazistas, do ponto de vista incomum de um torturador nazista. O narrador desse conto é o personagem Otto Dietrich zur Linde, exsubdiretor do campo de concentração de Tarniwitz, que vai ser fuzilado por tortura e assassinato. Na noite que precede sua execução, Zur Linde rememora sua vida e seus atos na construção do Terceiro Reich e descobre que o nazismo, intrinsecamente, é um fato moral, um despojar-se do velho homem, que está viciado, para vestir um novo... e que "la piedad por el hombre superior es el último pecado de Zarathustra". (Borges, 1996, p. 643). E ele confessa que quase comete esse pecado quando chega ao campo o admirável poeta judeu David Jerusalém. Zur Linde, então, ao destruir Jerusalém por haver se transformado no símbolo de uma detestada zona de sua alma, revela que agonizou com ele, morreu com ele e, de algum modo, se perdeu com ele; por essa razão, foi implacável.

Já "La muerte y la brújula" pode ser considerado um conto judeu não somente pelos nomes de seus personagens, mas pela sua precisão, por seu cálculo intelectual, por seu método cabalístico. ${ }^{68}$ Concebido como policial, segundo Harold Bloom (1995) "La muerte y la brújula" constitui um modelo do que há de mais valioso e mais enigmático 'em' e 'sobre' Borges; consiste em uma narrativa que enfoca o desfecho de $68 \mathrm{O}$ mecanismo de precisão que representa a Cabala é outro elemento a atrair Borges às Sagradas Escrituras, segundo Muñoz Rengel. Fishburn e Hughes (1990, p.71) definem o termo Cabala como um corpo de conhecimento religioso e experiência que busca proporcionar um meio de aproximação direta com Deus. Segundo os autores, a Cabala refere-se, também, em grande medida, à postulação de sistemas cosmológicos, ou seja, teorias da criação, manutenção e destino do mundo e a inter-relação de seus componentes. De acordo com o relato judaico da criação, a linguagem precedeu o ato da criação; daí a crença nas propriedades mágicas do Hebraico, a língua empregada por Deus. De acordo com os estudiosos, a capacidade de nomear as coisas seria, conseqüentemente, uma capacidade de criar. 
um combate de sangue entre o detetive Erik Lönnrot e o gângster judeu Red Scharlach, numa Buenos Aires visionária que, de acordo com o respeitado ensaísta norte-americano, tão freqüentemente é o contexto da fantasmagoria característica de Borges. Inimigos mortais, conforme sugere a cor vermelha dos seus nomes, são também duplos óbvios, o que faz com que o conto possa ser visto como um amálgama de Poe, Kafka e tantos outros duplos que se enfrentam.

O conto gira em torno de uma série de crimes e inicia com o assassinato do rabino Marcel Yarmolinsky, representante de Podólsk no Terceiro Congresso Talmúdico, cometido no Hôtel du Nord. Assim diz o narrador, associando a atitude individual do judeu às características da sua raça: "Nunca sabremos si el hotel le agradó. Lo aceptó con la antigua resignación que le había permitido tolerar tres años de guerra en los Cárpatos y tres mil años de opresión y de progroms" (Borges, 1996, p. 556).

Junto a seu corpo, uma nota com as palavras: "La primera letra del Nombre ha sido articulada" (Borges 1996: 500 v.I). Lönnrot, detetive encarregado do caso e racional como o Dupin de Poe, vai buscar para os crimes explicações rabínicas nos livros que o morto carrega consigo; entre eles, uma monografia sobre o Tetragrámaton, o livro dos Nomes de Deus, uma Vindicação da Cabala, um Exame da filosofía de Robert Fludd, uma tradução literal do Sepher Yezirah, uma Biografia do Baal Shem, uma Historia da Seita dos Hassidim, uma monografia sobre a nomenclatura divina do Pentateuco. O detetive deduz, com base nessa bibliografia, que a mensagem se refere ao Tetragrámaton, o nome secreto de JHVH, o Deus Javé. No mês seguinte, um outro morto é encontrado em um subúrbio a Oeste da cidade, constituindo a segunda letra do Nome, o que faz com que Lönnrot conclua que as mortes são sacrifícios místicos de alguma seita judaica. Um terceiro assassinato supostamente acontece no setor Leste, mas, nesse caso, sem cadáver; então já é possível verificar que o detetive está, aos poucos, sendo manipulado e atraído a uma armadilha, cujo cerco se completa numa mansão no Sul, nos arredores da cidade, quando é assassinado. Dessa forma, "La muerte y la brújula" constitui, também, uma narrativa que demonstra que ler é sempre uma espécie de re-escrita, de re-interpretação.

Segundo Lyslei Nascimento (2001), a atração de Borges pela Cabala, evidenciada em textos como "La muerte y la brújula", não parte da doutrina, mas de alguns procedimentos hermenêuticos e criptográficos, que lhe são peculiares. O seu interesse não seria, portanto, teoló- 
gico, filosófico ou místico, mas singularmente lúdico. Assim, essa aproximação de Borges à Cabala tem por objetivo proliferar possibilidades narrativas e não, como queriam os cabalistas, desentranhar segredos.

Também em "La muerte y la brújula" é possível verificar um dos temas teológicos mais enfocados por Borges: a oposição entre Caim e Abel, manifesta igualmente em outros contos e poemas. Note-se que Borges se interessa pela história bíblica dos dois irmãos e utiliza-a como simbolismo da interminável e tantas vezes mortal confrontação entre as pessoas. Entretanto, como é típico de Borges, no poema "Génesis, 4,8" a narrativa bíblica é alterada: "Fue el primer desierto/ Dos brazos arrojaron una gran piedra/ No hubo un grito. Hubo sangre/ Hubo por primera vez la muerte/Ya no recuerdo si fui Abel o Caín” (Borges, 1996. p.504 v.II).

No texto borgiano, os dois irmãos são dois pólos de uma mesma unidade, e seu mito transforma-se numa das maiores obsessões de Borges: a confusão das identidades e a relatividade de todas as coisas. Além de presente na encarniçada luta entre os duplos Lönnrot e Scharlach, as figuras de Caim e Abel se repetem em muitos outros textos.

Em "El fin", por exemplo, Borges retoma o mito numa história de um duelo a faca entre Martín Fierro e um negro que espera há sete anos para vingar a morte de seu irmão. O conto narra a tarde do combate em que o negro realiza seu destino, faz justiça a seu irmão e assume a identidade do outro: "ahora era nadie. Mejor dicho era el otro: no tenía destino sobre la tierra y había matado a un hombre" (Borges, 1996. p. 580, v.I ).

A noção panteísta de que um homem é todos os outros, segundo Jaime Alazraki (1983), implica a negação da individualidade ou a anulação da identidade individual; mais exatamente, a redução de todos os indivíduos a uma identidade geral e suprema que os contém e que, por sua vez, faz com que todos estejam contidos em cada um deles. Em "Los teólogos", os principais personagens, dois teólogos romanos, travam uma batalha secreta, ainda que ambos militem no mesmo exército e guerreiem contra o mesmo inimigo: as heresias. Um deles, Aureliano, denuncia o outro, Juan de Panonia, acusando-o de defender heresia panteísta. Juan de Panonia é, então, executado numa fogueira. Entretanto Aureliano, o acusador, comprova, ao chegar ao paraíso, "que para la insondable divinidad, él y Juan de Panonia (el ortodoxo y el hereje, el aborrecedor y el aborrecido, el acusador y la víctima) formaban una sola persona" (Borges, 1996, p. 619). 
A noção panteísta de igualar o ortodoxo e o herege, observa ainda Alazraki (1983, p. 80), está presente ao se pensar na fé e na crença dos cristãos, que nos tempos de Roma eram arremessados à arena dos circos para serem devorados pelas feras; no entanto, essas mesmas fé e crença, séculos mais tarde, acenderam uma fogueira cujas chamas aniquilaram milhares de homens que as renegavam. Os tempos transformam as vítimas em perseguidores. Assim, se a vítima pode ser o verdugo, se o ortodoxo pode ser o herege ou, ainda, se o acusador pode ser o acusado, como não aceitar a possibilidade de uma identidade única e universal de forma que cada homem seja parte da divindade em contato com o mundo? No entanto, para Borges, adverte ainda Alazraki, responder afirmativamente à questão não significa que ela seja real; significa tão somente que ela é uma tese esplêndida, tão esplêndida que "qualquer falácia cometida pelo autor resulta insignificante" (Borges, 1996, p. 26).

Da mesma forma, em "Tema del traidor y del héroe", a semelhança entre as mortes de César, Lincoln e Kilpatrick constituem mais uma referência à idéia de Borges de que qualquer homem é todos os homens e que qualquer acontecimento leva implícito em si todo o passado.

Também é recorrente nos contos de Borges a tese de que se alguém participa de uma entidade qualquer, ele é essa entidade; ou que uma circunstância similar unindo várias pessoas faz dessas pessoas uma só.

No poema "El truco", de Fervor de Buenos Aires, o conceito é enriquecido, ao aparecer perpetuado no fato de que todos que realizam uma mesma ação básica e ritual perdem a identidade individual e se tornam, de certa forma, imortais.

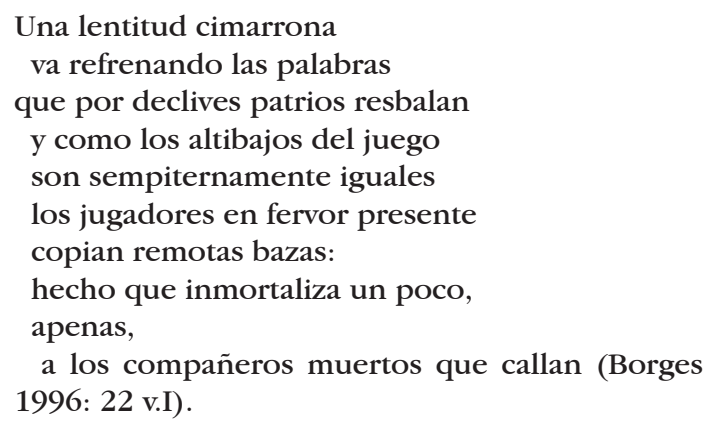


A idéia é a de que os jogadores do passado, mortos, voltam a viver nos jogadores que, hoje, reproduzem as mesmas apostas; assim, a repetição de um ato ritualizado suspende e apaga o tempo histórico e confere eternidade aos que o praticam. ${ }^{69}$

Em "La forma de la espada" verifica-se a presença da mesma tese. Um irlandês, chamado de "El inglés", conta a história de uma cicatriz que tem no rosto; fica-se sabendo que ele lutou pela independência da Irlanda e foi traído por um companheiro, John Vincent Moon, a quem salvara a vida. Antes de ser preso, no entanto, "El inglés" consegue marcar para sempre o rosto do traidor com uma meia lua de sangue. No final surpreendente do conto o narrador confessa que é o traidor e não o traído. Esclarece o narrador:

Lo que hace un hombre es como si lo hicieran todos los hombres. Por eso no es injusto que una desobediencia en un jardín contamine al género humano; por eso no es injusto que la crucifixión de un solo judío baste para salvarlo. Acaso Schopenhauer tiene razón: yo soy los otros, cualquier hombre es todos os hombres, Shakespeare es de algún modo el miserable John Vincent Moon (Borges, 1996, p. 550, negrito meu).

Assim, o traidor é o traído e somente no epílogo sua verdadeira identidade nos é revelada. Da mesma forma, a surpresa final da troca de identidade é utilizada como técnica da narrativa policial "Abenjacán el Bojarí, muerto en su laberinto". Abenjacán, o Bojarí, rei de uma tribo nilótica é o protagonista do conto e causou espanto ao chegar ao porto de Pentreath escoltado por um escravo negro e um leão da cor do sol. Tirano, escapara de uma sublevação de seu povo no deserto do Sudão e, em companhia de seu primo, o vizir Zaid (que tinha fama de covarde), fugira, carregando um tesouro, um escravo e um leão. Na fuga, Abenjacán matou Zaid, procurou outras terras e chegou a Cornwall. Mas, em sonhos, o fantasma do primo prometeu vingança e, para se esconder, Abenjacán construiu uma enorme casa-labirinto no topo de uma elevação da costa, passando a morar no centro dela. Todo o esforço do rei Abenjacán, no entanto, foi em vão. $O$ fantasma de Zaid penetrou no labirinto e conseguiu matá-lo, ao leão e ao escravo, destroçando-lhes as faces. No final do conto, o leitor é informado de que o mistério da morte de Abenjacán é elucidado por Unwin, muitos anos depois; a partir de uma série de inferências, esse personagem/ 69 Ver Emir Monegal $(1987,102)$ e Ernesto Sábato $(1976,72)$. 
detetive conclui que o homem que dizia ser Abenjacán era, na verdade, Zaid, o covarde, que tinha roubado o tesouro do rei e fugido com ele. Consciente de que Abenjacán o perseguiria, construiu um labirinto, suficientemente vistoso para que as notícias dele chegassem até Bojarí, atraindo-o. O labirinto foi então construído não pelo perseguido, mas pelo perseguidor, e seu propósito não era se esconder do perseguidor, mas atraí-lo.

Note-se que essa mesma tese panteísta também está presente no desconhecido planeta Tlön, onde "Todos los hombres, en el vertiginoso instante del coito, son el mismo hombre. Todos los hombres que repiten una línea de Shakespeare, son William Shakespeare" (Borges, 1996, p. 483 v.I).

Assim, segundo o panteísmo, se a individualidade não existe, se qualquer homem pode ser todos os homens, Judas pode ser Jesus. Essa é uma hipótese apresentada por Borges no conto-ensaio "Tres versiones de Judas", no qual o teólogo Nils Runeberg questiona a traição do apóstolo Judas Iscariotes em três diferentes interpretações. Inicialmente afirma que de algum modo Judas reflete Jesus, uma vez que o Verbo se fez mortal em Cristo e Judas, seu discípulo, como representante de todos os homens, inclusive do Verbo, fez um sacrifício condigno: rebaixou-se a delator, o pior delito que a infâmia suporta. Assim, a traição de Judas Iscariotes não foi casual, foi um fato predeterminado na redenção. A segunda tese sustenta que se para maior glória do Senhor o asceta mortifica e envilece a carne, Judas fez a mesma coisa com o espírito: renunciou à honra, ao bem, à paz, ao reino dos céus, como outros, menos heroicamente ao prazer (Borges, 1996, p.575). Suas culpas foram, pois, premeditadas com lucidez terrível; agiu com enorme humildade, acreditou-se indigno de ser bom. Por fim, Runenberg propõe a tese de que Deus se fez totalmente homem, porém homem até a infâmia; para nos salvar, pôde escolher qualquer dos destinos que tramam a perplexa rede da história; pôde ser Alexandre ou Pitágoras ou Rurik ou Jesus; mas escolheu um ínfimo destino: foi Judas. Dessa forma, o verdadeiro Cristo foi Judas que, sabendo de sua condenação, vendeu a Cristo para que ele salvasse a humanidade; e o verdadeiro sacrifício foi de Judas e não de Cristo, que tinha seu lugar seguro na glória. ${ }^{70}$

Alazraki (1983) ainda observa que a forma ensaística do conto deve-se a uma constante mistura do real com o fictício que permeia 70 A crucificação de Jesus e as contradições de um sacrifício protagonizado por um Deus onisciente é tema de muitos textos de Borges como "El Biathanatos" (BORGES, 1996, p. 78 v.II) e o poema "Cristo en la cruz" ( BORGES, 1996, p. 457 v.III). 
toda a narrativa. Autores fictícios como Runeberg, Abramovicz, Erjford e Hladík (personagem de "El milagro secreto") convivem com De Quincey, Euclides da Cunha, T.E. Lawrence e Almafuerte. Teorias apócrifas misturam-se a citações de De Quincey, de Lawrence, de textos bíblicos, como Mateus 12:31; Lucas 9:1; I Coríntios 1:31; João 1:10 e 12:6; Isaías 53:2-3. Assim, é quase impossível, sem prévia verificação, distinguir o enganoso do genuíno, o que constitui um estratagema de Borges para confundir o leitor e forçá-lo, dessa forma, a aceitar o falso como verdadeiro e fazer-lhe sentir que todos podem ser todos, como Judas pode ser Jesus.

Em seus textos Borges não demonstra convicção absoluta, mas o prazer de estar sempre procurando novas respostas. E nessa busca ele envolve também o leitor, ao libertá-lo das idéias pré-concebidas e das limitações do mundo; ao ensiná-lo a duvidar dos dogmas e ao expor a fragilidade das verdades irrestritas. Como os filósofos de Tlön, Borges busca o prazer imaginativo nas idéias religiosas e metafísicas e brinca com tais idéias em sua literatura, levando seu leitor a acreditar que elas poderiam ser, talvez, suas convicções. 


\section{Referências}

ALAZRAKI, Jaime. La prosa narrativa de Jorge Luis Borges. Madrid: Gredos, 1983.

BLOOM, Harold. O cânone ocidental. Tradução de Marcos Santarrita. Rio de Janeiro: Objetiva, 1995.

BORGES, Jorge Luis. "Abenjacán el Bojarí, muerto em su laberinto". In: Obras completas I. El Aleph. Barcelona: Emecé, 1996.

. "Emma Zunz". In: Obras completas I. El Aleph. Barcelona: Emecé, 1996.

. "Deutsches Requiem". In: Obras completas I. El Aleph. Barcelona: Emecé, 1996.

. "El fín". In: Obras completas I. Ficciones. Barcelona: Emecé, 1996.

. "El tiempo y J.W. Dunne". In: Obras completas II. Otras Inquisiciones. Barcelona: Emecé, 1996.

. "Génesis, 4, 8". In: Obras completas II. El oro de los tigres. Barcelona: Emecé, 1996.

. "La forma de la espada." In: Obras completas I. Ficciones. Barcelona: Emecé, 1996.

. "La muerte y la brújula". In: Obras completas I. Ficciones. Barcelona: Emecé, 1996.

. "Los teólogos". In: Obras completas I. El Aleph. Barcelona: Emecé, 1996.

. "Tema del traidor y del héroe". In: Obras completas

I. Ficciones. Barcelona: Emecé, 1996.

. “Tlön, Uqbar, Orbis Tertius”. In: Obras completas I.

Ficciones. Barcelona: Emecé, 1996. 
. "Otras inquisiciones (1952)". In: Obras completas II.

Barcelona: Emecé, 1996.

CANDIDO, Antonio et al. "A personagem do romance". In: A personagem de ficção. São Paulo: Perspectiva, 1998.

FISHBURN y HUGHES. Un dicionario de Borges. Tradução de David Susel. Buenos Aires: Torres Agüero, 1990.

MOLLOY, Sylvia. "Jorge Luis Borges, confabulador (1899 - 1986)". Revista Ibero Americana, Pittsburg, n. 141, p. 801-808, out-dez, 1987.

MONEGAL, Emir R. Uma poética da leitura.Tradução de Irlemar Chiampi. São Paulo: Perspectiva, 1980.

MUNÕZ RANGEL. En qué creía Borges. S/d. Disponível em http:// members.fortunecity.com/mundopoesia2/articulos/enquecreiaborges. htm. Acesso em 28/mar/2007.

NASCIMENTO, Lyslei de Souza. Vestígios da tradição judaica: Borges e outros rabinos. 2001. Tese - Curso de Pós Graduação em Letras, Universidade Federal de Minas Gerais, Belo Horizonte.

SÁBATO, Ernesto. "Los relatos de Jorge Luis Borges”. In: Jorge Luis Borges, edición de Jaime Alazraki. Madrid: Taurus, 1976.

VÁZQUEZ, María Esther. Borges: imagines, memórias, diálogos. Caracas: Monte Ávila, 1977. 